\title{
REKONSTRUKSI BATAS BIDANG TANAH MENGGUNAKAN JARINGAN REFERENSI SATELIT PERTANAHAN Kariyono' $^{1}$, Eko Budi Wahyono ${ }^{2}$, Tanjung Nugroho ${ }^{3}$
}

\begin{abstract}
ORS is a GNSS station operating continuously for 24 hours. It is also used as a reference for determining a, both as a real time and as post-processing. Cors in BPN RI is known as Jaringan Referensi Satelit Pertanahan (JRSP). BPN RI has not yet optimized the use IRSP to reconstruct parcel boundaries. The research is aimed at examine the IRSP in reconstructing parcel boundaries. The analysis on lateral displacement tolerance and the difference on the area of parcles was based on technical guidance of PMNA/KBPN No. 3 of 1997 and the $t$ test using the level of significance of $(\alpha)=5 \%$. The results were: I)The reconstruction of parcels using JSRP can be done by firstly implementing the coordinate transfer and the most accurate Helmert coordinate transfer method using a posteriori variance of $(\sigma 2)=1.143020313$; 2) The lateral transformation and the difference on parcel areas using IRSP suited the tolerance and the result of the test did not show any significance level of $(\alpha)=5 \%$.
\end{abstract}

Keywords: reconstruction, parcel boundaries, IRSP

\begin{abstract}
Abstrak: CORS merupakan stasiun GNSS yang beroperasi secara kontinyu selama 24 jam sebagai acuan penentuan posisi, baik secara real time maupun post-processing. CORS di BPN RI dikenal sebagai Jaringan Referensi Satelit Pertanahan (JRSP). BPN RI belum mengoptimalkan pelaksanaan rekonstruksi batas bidang tanah menggunakan IRSP. Tujuan dalam penelitian ini adalah untuk menguji IRSP dalam pelaksanaan rekonstruksi batas bidang tanah. Analisis terhadap toleransi pergeseran lateral dan perbedaan luas bidang tanah hasil rekonstruksi batas bidang tanah menggunakan IRSP berdasarkan Juknis PMNA/KBPN No 3 tahun 1997 dan uji t dengan taraf signifikansi $(\alpha)=5 \%$. Hasil penelitian ini adalah : I)Rekonstruksi batas bidang tanah tanah menggunakan IRSP dapat di laksanakan dengan terlebih dahulu melaksanakan transformasi koordinat dan metode transformasi koordinat yang paling teliti adalah metode Helmert dengan varian posteriori $(\sigma 2)=1.143020313$; 2)Pergeseran lateral dan perbedaan luas bidang tanah hasil rekonstruksi batas bidang tanah menggunakan JRSP memenuhi syarat toleransi dan dari uji t dengan taraf signifikansi $(\alpha)=5 \%$ tidak terdapat perbedaan yang signifikan.
\end{abstract}

Kata Kunci: Rekonstruksi, Batas Bidang Tanah , JRSP

\section{A. Pendahuluan}

Perkembangan teknologi dan ilmu pengetahuan sekarang ini sangatlah pesat. Hal ini juga memacu perkembangan teknologi alat ukur pemetaan dan metode pengolahan data, serta kecepatan dalam

${ }^{1}$ Penulis adalah Analis Kendali Mutu Pengukuran dan Pemetaan, Bidang Survei Pengukuran dan Pemetaan, Kementerian Agraria dan Tata Ruang/BPN Kantor Wilayah Provinsi Sulawesi Tenggara, Email: kariyono.atrbpn@gmail.com

2 Penulis adalah staf pengajar STPN Yogyakarta, email : ebudiw65@yahoo.co.id

3 Penulis adalah staf pengajar STPN Yogyakarta, email : tj.groho@gmail.com melakukan pemetaan. Salah satu dari perkembangan teknologi penentuan posisi berbasiskan satelit adalah Global Navigation Satellite System (GNSS) Continuous Operating Reference System (CORS). CORS merupakan stasiun GNSS yang beroperasi secara kontinyu selama 24 jam sebagai acuan penentuan posisi, baik secara real time maupun post-processing.

CORS di Kementerian Agraria dan Tata Ruang/ BPN dikenal sebagai Jaringan Referensi Satelit Pertanahan (JRSP) yang merupakan sebuah teknologi handal dan layak dengan sistem memberi ketelitian tinggi untuk penentuan posisi di permukaan bumi 
(Direktorat Pengukuran Dasar BPN RI 2009, 1).JRSP dibangun untuk mempermudah dan mempercepat tercapainya tertib pertanahan, meningkatnya produktifitas dan akurasi, serta meningkatnya kualitas pelayanan kepada masyarakat di bidang survei dan pemetaan (Direktorat Pengukuran Dasar BPN RI 2009,10). Permasalahan sistem koordinat pada kegiatan survei dan pemetaan dapat teratasi karena pengukuran dengan receiver berbasiskan GNSS menggunakan sistem koordinat yang bereferensi global (georeference).

JRSP dengan aktivitasnya yang kontinu, dapat juga diterapkan untuk dynamic cadastre, yaitu sebagai kerangka geodetik yang dinamis dan memiliki akurasi homogen. Dengan adanya referensi yang dinamis, maka titik titik kerangka JRSP dapat mengatasi permasalahan yang ditimbulkan oleh efek geodinamika (Direktorat Pengukuran Dasar BPN RI 2009, 6). Dengan mengembangkan dynamic cadastre, dinamika posisi suatu titik dapat dipantau dan kemudian dapat dilakukan koreksi terhadap posisi tersebut sesuai dengan kondisi perubahan yang terjadi. Dengan adanya fakta Indonesia sebagai dynamicregion yang paling cocok diterapkan adalah semy dynamic datum dengan epoch reference tertentu (Andreas 2011, 7).

Dengan adanya JRSP yang dapat diterapkan untuk dynamic cadastre tersebut sangat penting dijadikan acuan dalam perubahan posisi titik ikat dan batas bidang tanah yang telah diukur dan didaftar pada waktu lampau untuk terjaminya kepastian hukum terhadap obyek hak. Kepastian hukum terhadap obyek hak atas tanah meliputi kepastian letak, batas dan luas bidang tanah (Abidin 2005, 2). Seringkali dijumpai tanda batas bidang tanah hilang atau bergeser dan untuk mengatasi hilangnya tanda batas fisik bidang tanah tersebut perlu dilakukan rekonstruksi batas bidang tanah.

Permasalahan rekonstruksi batas bidang dengan menggunakan teknologi JRSP adalah pengukuran terdahulu yang menggunakan kerangka referensi yang berbeda yaitu JRSP BPN RI terikat pada kerangka referensi global International Terestrial Reference Frame 2008 (ITRF 2008) sedangkan sebelumnya berdasarkan Datum Geodesi Nasional 1995 (DGN 95) dengan acuan International Terestrial Reference Frame 1992 (ITRF 92) pada epoch 1993. Menurut Mustaqim (2013, 51) menyatakan akibat penggunaan sistem kerangka referensi yang berbeda pergeseran lateral rata-rata sebesar 0,991 meter kearah 43,953 ${ }^{\circ}$ dari utara, dimana base station pengukuran menggunakan ITRF 2008 sedangkan TDT pengukuran menggunakan DGN 95. Dengan adanya hal tersebut akan berdampak terhadap pekerjaan survei dan pemetaan di lingkungan Kementerian Agraria dan Tata Ruang/BPN salah satunya dalam kegiatan rekonstruksi batas bidang tanah.

Dengan adanya pergeseran posisi tersebut maka koordinat (TDT) dan batas bidang tanah berdasarkan pengukuran dengan sistem lama tidak bisa secara langsung digunakan dalam pelaksanaan rekonstruksi batas bidang tanah. Maka perlu adanya pengukuran koordinat pengamatan antar epoch reference (Nugroho 2013, 259). Koordinat tersebut dapat bermanfaat untuk mengetahui besar dan arah dislokasi posisi titik ikat dan batas bidang tanah serta dapat digunakan untuk melakukan tranformasi koordinat dalam suatu pemetaan kadastral antar waktu sehingga dapat menunjang kesahihan data pendaftaran tanah sehingga mampu menjamin kepastian hukum obyek hak atas tanah.

\section{B. Tinjauan Pustaka}

\section{Titik Dasar Teknik}

Menurut pasal 1 butir 13 PP No.24/1997, Titik Dasar Teknik adalah titik yang mempunyai koordinat yang diperoleh dari suatu pengukuran dan perhitungan dalam suatu sistem tertentu yang berfungsi sebagai titik kontrol atau titik ikat untuk keperluan pengukuran dan rekonstruksi batas. TDT dibagi ke dalam beberapa orde berdasarkan tingkat ketelitian dan kerapatan titik. Spesifikasi TDT dapat dilihat pada tabel 1 berikut ini: 
Tabel 1. Spesifikasi Titik Dasar Teknik

\begin{tabular}{|c|cc|c|}
\hline TDT & Kerapatan & Instansi & $\begin{array}{c}\text { Metode } \\
\text { Pengukuran }\end{array}$ \\
\hline Orde $\mathrm{o}$ & $\geq 50 \mathrm{~km}$ & Bakosurtanal & GPS \\
\hline Orde 1 & \pm 20 s.d $50 \mathrm{~km}$ & Bakosurtanal & GPS \\
\hline Orde 2 & $\pm 10 \mathrm{~km}$ & BPN & GPS \\
Orde 3 & \pm 1 s.d $2 \mathrm{~km}$ & BPN & GPS \\
Orde 4 & $\pm 150 \mathrm{~m}$ & BPN & Poligon \\
\hline
\end{tabular}

Sumber: SNI Jaring Kontrol Horisontal Tahun 2002

\section{Rekonstruksi Batas Bidang Tanah}

Secara bahasa "merekonstruksi" adalah mengembalikan dalam arti meletakkan kembali patok-patok batas bidang tanah yang hilang atau berpindah tempat namun yang telah terukur sebelumnya ke posisi asalnya (artinya panjang sisi, bentuk, luas dan letak bidang tanah sama antara sebelum dan sesudah rekonstruksi) berdasarkan dokumen yang tersedia atau alat bukti valid lainnya (Mardiyono dkk. 2009, 72). Dokumen yang diperlukan untuk keperluan rekonstruksi yang tersedia bisa berbagai macam, mulai dari Gambar Ukur, Surat Ukur, Peta Pendaftaran dan dokumen lainnya (Deputi Bidang Informasi Pertanahan BPN 2001, 45). Untuk merekonstruksi batas bidang tanah, data yang paling utama adalah data dari Gambar Ukur karena data tersebut berasal dari pengamatan di lapangan.

Prinsip rekonstruksi adalah pegangan, acuan atau panduan yang tidak perlu dibuktikan karena kebenarannya secara umum telah terwujud dengan sendirinya. Prinsip-prinsip rekonstruksi menurut Mardiyono dkk. (2009, 73) adalah sebagai berikut:

a) Semuayang tercantum dalam dokumen pengukuran dianggap benar;

b) Metode rekonstruksi minimal sepadan dengan metode saat pengukuran;

c) Hasil rekonstruksi merupakan hasil baru yang minimal memiliki ketelitian yang sepadan dengan sebelumnya;

d) Rekonstruksi adalah proses surveyor menemukan kembali batas yang benar.
Prinsip rekonstruksi batas bidang tanah tersebut diterapkan dalam rekonstruksi batas bidang tanah baik secara terestris maupun menggunakan GPS. Secara terestris rekonstruksi titik batas bidang tanah menggunakan pita ukur/EDM sebagai alat ukur jarak, theodolite/total station sebagi alat ukur sudut. Menurut Abidin (2006, 232) pada prinsipnya ada dua metode perekonstruksian batas dengan GPS yang dapat diaplikasikan, yaitu metode langsung dan metode tidak langsung. Metode langsung perekontruksian titik-titik batas bidang tanah dilakukan hanya menggunakan GPS, yaitu dengan langsung mencari koordinat titik-titik batas bidang tanah yang diinginkan dan metode diferensial GPS secara realtime perlu diaplikasikan. Sedangkan metode tidak langsung dilaksanakan dengan dua buah titik bantu di sekitar lokasi bidang tanah ditentukan koordinatnya secara diferensial dengan GPS terhadap suatu titik dasar teknik terdekat. Dari dua titik bantu GPS tersebut dengan menggunakan data jarak dan sudut, yang dihitung dari data koordinat titik batas dan titik bantu, maka titik batas dapat direkonstruksikan kembali di lapangan. Perkembangan teknologi penentuan posisi dengan JRSP yang dikembangkan oleh BPN RI dapat digunakan untuk pelaksanaan rekonstruksi batas bidang tanah. Untuk mengetahui rekonstruksi batas bidang tanah dengan JRSP memenuhi toleransi yang ditetapkan atau tidak perlu ada pegujian terhadap hasil dari rekonstruksi batas bidang tanah tersebut.

Untuk menghasilkan rekonstruksi batas bidang tanahyang akurat perlu adanya standarisasi. Dalam rekonstruksi batas bidang tanah belum ada standarisasi khusus terhadap ketelitian hasil dari rekonstruksi. Di lingkup pengukuran dan pemetaan di BPN RI telah dikeluarkan Petunjuk Teknis PMNA/KBPN Nomor 3 Tahun 1997 Materi Pengukuran dan Pemetaan Pendaftaran Tanah yang mengatur tentang toleransi pergeseran posisi dan luas terhadap pengukuran lebih dari 2(dua) kali. Sehingga diasumsikan bahwa rekonstruksi titik 
batas bidang tanah terdapat toleransi pergeseran posisi yang diperbolehkan setiap titik adalah $10 \mathrm{~cm}$ untuk daerah pemukiman dan $25 \mathrm{~cm}$ untuk daerah pertanian. Dalam hal luas bidang tanah toleransi luas adalah $1 \frac{1}{2} \sqrt{ } \mathrm{L}$ (Petunjuk Teknis PMNA/K.BPN No. 3 Tahun 1997).

\section{Gambar Ukur dan Metoda Pengukurannya}

Petunjuk Teknis PMNA/K.BPN No. 3 Tahun 1997 (2002, V-15) menyebutkan bahwa Gambar Ukur pada prinsipnya adalah dokumen yang memuat data hasil pengukuran bidang tanah berupa jarak, sudut, azimuth maupun gambar bidang tanah dan situasi sekitarnya. Catatancatatan pada Gambar Ukur harus dapat digunakan sebagai data rekontruksi batas bidang tanah. Dalam penelitian ini menggunakan Gambar Ukur dari pengukuran terestris. Metode pengukuran secara terestris diikatkan terhadap Titik Dasar Teknik (TDT). Titik Dasar Teknik adalah titik yang mempunyai koordinat yang diperoleh dari suatu pengukuran dan perhitungan dalam suatu sistem tertentu yang berfungsi sebagai titik kontrol atau titik ikat untuk keperluan pengukuran dan rekonstruksi batas.

Metode pengikatan yang sering digunakan adalah metode offset cara trilaterasi sederhana dan metode polar dengan unsur azimuth dan jarak, tiap hasil ukuran dicantumkan dalam Gambar Ukur sesuai dengan aturan penulisan, kecuali pada pengukuran yang dilaksanakan dengan peralatan digital seperti total station, format perekaman datanya akan berlainan (Nugroho 2004, 10).

\section{Sistem Kerangka Referensi}

ITRF direpresentasikan dengan koordinat dan kecepatan dari sejumlah titik yang tersebar di seluruh permukaan bumi, dengan menggunakan metode-metode pengamatan VLBI, LLR, GPS, SLR, dan DORIS (Subarya 2004, 12). Jaring kerangka ITRF dipublikasikan setiap tahunnya oleh IERS, dan diberi nama ITRF-yy, dalam hal ini yy menunjukkan tahun terakhir dari data yang digunakan untuk menentukan kerangka tersebut (Badan Standarisasi Nasional. Standar Nasional Indonesia 19-6724-2002). Sebagai contoh ITRF 92 adalah kerangka koordinat dan kecepatan yang dihitung pada tahun 1993 dengan menggunakan data IERS sampai akhir tahun 1992. ITRF dapat diperbaharui secara terus-menerus dan yang terbaru adalah ITRF 2008. Pada saat ini kerangka ITRF terdiri dari sekitar 300 titik di permukaan bumi, yang mempunyai koordinat dengan ketelitian sekitar 1-3 cm serta kecepatan dengan ketelitian sekitar 2-8 mm/tahun (Abidin 2001, 45).

Berdasarkan Surat Keputusan Kepala Bakosurtanal Nomor: HK.02.04/II/KA/96 tanggal 12 Februari 1996 menetapkan bahwa setiap kegiatan survei dan pemetaan di wilayah Republik Indonesia harus mengacu DGN 95 atau yang biasa disebut sferoid WGS 84. Perwujudan DGN 95 di lapangan diwakili oleh sejumlah titik Jaring Kerangka Geodesi Nasional (JKGN) orde o dan 1 yang menyebar di seluruh wilayah Indonesia hasil pengukuran dengan teknologi GPS oleh Bakosurtanal (Badan Informasi Geospasial). Di lingkungan Kementerian Agraria dan Tata Ruang/BPN, JKGN yang dikembangkan disebut KDKN di mana pengukurannya dengan teknologi GPS dengan ellipsoid referensi WGS 84 yang menyebar di Indonesia baik orde 2, orde 3 maupun orde 4 dengan bereferensi pada DGN 95 (Sunantyo dkk. 2011, 32).

\section{Pergerakan Kerak Bumi}

Pergerakan lempeng tektonik memiliki pengaruh yang besar pada berbagai fenomena alam, misalnya menyebabkan terbentuknya sesar dan juga terjadinya gempa bumi (Meilano dkk.2012, 2). Bersamaan dengan gempa terjadi pergeseran titik secara dramatis kisaran centimeter hingga meter.

Dinamika kerak bumi seperti pergerakan lempeng, deformasi pada batas antar lempeng, deformasi akibat mekanisme gempa bumi merupakan 
beberapa contoh yang memperlihatkan sifat bumi dinamis, disamping bentuk dinamika lainnya yang begitu kompleks dan beragam. Sifat dinamis bumi ini akan memberikan konsekuensi terhadap status geometrik jaring titik kerangka dasar pemetaan. Salah satu contoh hasil penelitian Abidin dkk (2009, 283) pasca gempa Yogyakarta yang terjadi pada 2006 memperlihatkan hasil deformasi pascaseismiknya dalam arah horizontal adalah sekitar o,3 sampai 9,1 $\mathrm{cm}$.

Proses geodinamika dan deformasi sedikit banyaknya pasti akan mempengaruhi status geometrik titik-titik kerangka dasar pemetaan. Akibat proses geodinamika dan deformasi, bench Mark/ tugu-tugu titik kerangka dasar pemetaan dapat berubah posisinya, sehingga akan mempengaruhi nilai koordinat yang telah didefinisikan sebelumnya.Untuk mengetahui pergerakan titik perlu adanya survei deformasi dan geodinamika. Survei deformasi untuk mengetahui perubahan kedudukan titik secara absolut maupun relatif, sedangkan survei geodinamika untuk memantau pergerakan bumi yang sedang berlangsung.

Jaring Kontrol Geodesi Nasional (JKGN) sebagai titik ikat pengukuran dan pemetaan serta untuk rekonstruksi batas dengan adanya fakta bahwa Indonesia adalah dynamic region rentan terhadap pergerakan lempeng tektonik sehingga kondisi geometriknya berubah sewaktu waktu, maka pendefinisian semi dynamic datum pada epoch reference tertentu perlu diperhatiakan. Menurut Andreas (2011, 4) dengan adanya epoch reference tersebut dapat mengadopsi pengaruh deformasi dan geodinamika terhadap set (kumpulan) koordinat dengan pendekatan transformasi ketika melakukan proses rekonstruksi batas bidang tanah atau redefinisi sistem.

\section{Transformasi Koordinat}

Untuk dapat melaksanakan transformasi koordinat, diperlukan titik sekutu atau commonpoint (Jurusan Teknik Geodesi FTSP ITB 1997, 57). Titik sekutu ini merupakan titik-titikyang berada dalam sistem koordinat lama dan sistem koordinat baru. Titik sekutu digunakan untuk mengetahui besarnya parameter transformasi (skala, rotasi, translasi). Setelah parameter diketahui nilainya (berdasarkan hitungan), maka koordinat titik lainnya dalam sistem koordinat lama dapat ditransformasikan ke sistem koordinat baru. Metode transformasi koordinat yang sering digunakan oleh Badan Pertanahan Nasional adalah metode Helmert, metode Affine dan Metode Lauf.

Metode Helmert dikenal sebagai transformasi sebangun (mempertahankan bentuk, sedang ukuran dilepas) dan dibutuhkan minimal 2 titik sekutu. Metode Affine dan Lauf ini dikenal transformasi tidak sebangun dalam arti ukuran dan bentuk dilepas dan jumlah minimal titik sekutu adalah 3 buah. Metode Affine cakupan wilayahnya kurang dari 36 x 36 km², sedangkan metode Lauf cakupan wilayahnya 300 x $300 \mathrm{~km}^{2}$ (Kurniawan dkk. 2006, 5).

\section{Jaringan Referensi Satelit Pertanahan}

GNSS merupakan sistem satelit navigasi dan penentuan posisi geospasial dengan cakupan dan referensi global yang menyediakan informasi posisi dengan ketelitian bervariasi, yang diperoleh dari waktu tempuh sinyal radio yang dipancarkan dari satelit dan ditangkap oleh receiver (Roberts dkk. 2004 dalam Sunantyo 2010, 17). Beberapa satelit navigasi yang merupakan bagian dari GNSS diantaranya adalah GPS milik Amerika Serikat, GLONASS milik Rusia, Galileo milik Eropa, Compass milik China, the Indian Regional Navigation Satellite System (IRNSS) milik India, dan Japan'sQuasi-Zenith Satellite System (QZSS) milik Jepang.

CORS adalah salah satu teknologi berbasis GNSS yang berwujud suatu jaring kerangka geodetikyang pada setiap titik jaringnya terdapat receiver yang berguna untuk menangkap sinyal dari satelit-satelit GNSS yang beroperasi secara kontinyu. CORS dapat 
digunakan sebagai stasiun acuan dalam penentuan posisi relatif, baik secara real time maupun postprocessing, dengan stasiun CORS sebagai single base ataupun sebagai multi base.

JRSP merupakan pengembangan teknologi CORS atau teknologi untuk menentukan posisi secara global menggunakan GNSS. Stasiun referensiJRSP dibangun secara permanen pada lokasi yang stabil di beberapa kantor pertanahan yang ada di Indonesia dengan jarak antar stasiun referensi sekitar $\pm 30-70 \mathrm{~km}$ (Direktorat Pengukuran Dasar BPN RI. 2009, 8). Stasiun referensi digunakan oleh pengguna (user) atau rover sebagai referensi dalam penentuan posisi atau koordinat suatu titik atau kumpulan titik pada suatu cakupan atau area secara real time maupun post processing.

Transfer data JRSP dapat dilakukan dengan 2 (dua) cara yaitu via radio modem dan via internet (Sunantyo2009, 4). Pada transfer data via radio modem range tergantung kekuatan dari radio modem. Melalui internet, data hasil pengamatan dapat diakses untuk penggunaan secara post processing maupun real time. Data dalam post processing diakses dalam format RINEX sedangkan untuk penggunaan secara real time data hasil pengamatan diakses dengan NTRIP (Networked Transport of RTCM via Internet Protocol). Konfigurasi sistem JRSP dapat dilihat pada gambar 1 berikut:

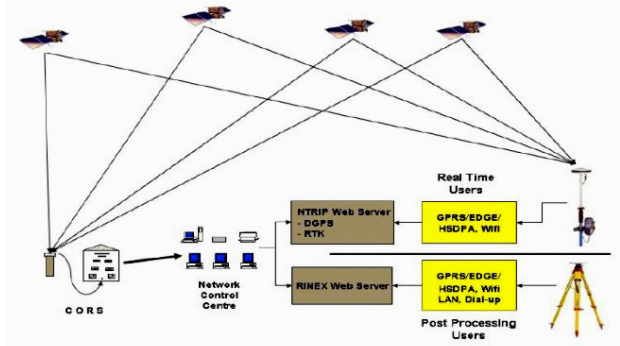

Gambar I. Konfigurasi Sistem JRSP (Sunantyo, 2009)

Dalam penelitian ini rekonstruksi batas bidang tanah menggunakan JRSP dilaksanakan secara langsung. Pelaksanaan rekonstruksi batas bidang tanah secara langsung dengan base station JRSP digunakan sebagai titik acuan yang telah diketahui koordinatnya, sedangkan receiver digunakan sebagi rover yang bergerak mencari koordinat dari titik batas bidang tanah yang telah diketahui koordinatnya. Selain lokasi yang terbuka dan bebas dari obstruksi, pengukuran metode real time mensyaratkan adanya jaringan internet pada lokasi bidang tanah yang akan diukur, sehingga diperlukan media komunikasi internet melalui suatu provider.

Pelaksanaanya rekonstruksi batas bidang tanah dengan JRSP menggunakan data koordinat yang ada dalam Gambar Ukur, kemudian koordinat tersebut dicari di lapangan dengan metoderealtime. Konsepnya dapat dilihat pada gambar 2 berikut:

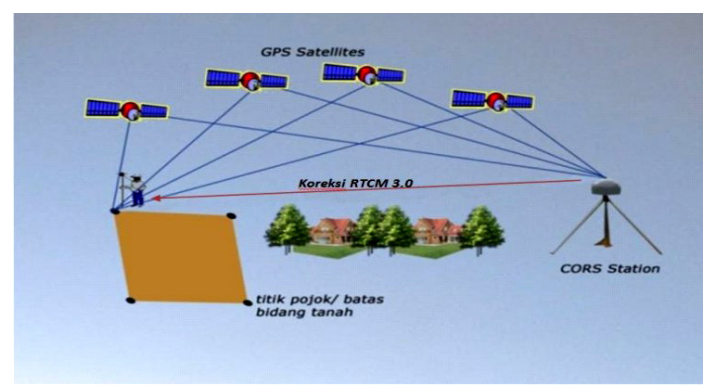

Gambar 2. Pelaksanaan Rekonstruksi Batas Bidang Tanah Secara Langsung Menggunakan JRSP (Abidin,2006)

\section{Metode Penelitian}

\section{Lokasi Penelitian}

Penelitian dilaksanakan di Desa Banyuraden, Kecamatan Gamping, Kabupaten Sleman. Base station yang digunakan adalah base station Kantor Pertanahan Kabupaten Sleman dengan koordinat $\mathrm{X}=293486.407, \mathrm{Y}=647745.779$ dan $\mathrm{Z}=\mathbf{2 5 6 . 7 9 1 .}$ Antena dan receiver base station nya dapat di lihat pada gambar 3 berikut:

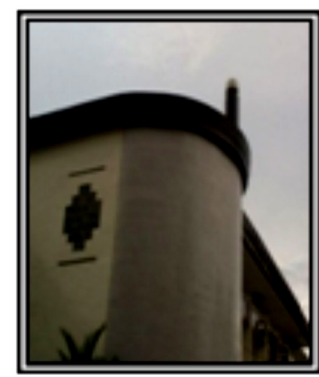

(a)

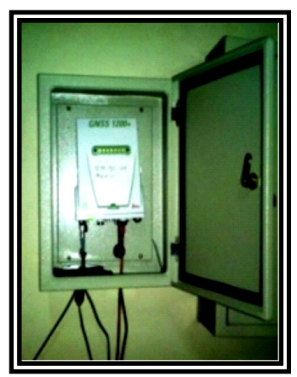

(b)
Gambar 3 (a) antena EICA AR25 LEIT

(b)receiver Leica GRX 1200+GNSS. (Sumber:

Kantor Pertanahan Kab. Sleman, 2014) 


\section{Data}

Data yang digunakan dalam penelitian antara lain: (a) data koordinat hasil pengukuran bidang tanah secara terestris yang diperoleh tanggal 19 Februari 2014 di lokasi penelitian Desa Banyuraden; (b) data koordinat hasil pengukuran receiver GNSS yang terformat dalam RINEX (pengukuran post processing) yang diperoleh tanggal 20 dan 21 Februari 2014 di Desa Banyuraden; (c) koordinat TDT orde 3 pada Buku Tugu tahun 1996 di lokasi penelitian Desa Banyuraden; (d) Data pergeseran lateral dan perbedaan luas bidang tanah hasil rekonstruksi batas bidang tanah menggunakan JRSP yang diperoleh tanggal 28 Februari 2014 di Desa Banyuraden.

\section{Peralatan}

Peralatan yang digunakan dalam penelitian meliputi: (a) Receiver tipegeodetik double frequency sebanyak 2 buah merk Topcon Hiper Ga (Base dan Rover); (b) Rover CORS merk JAVAD TRIUMP-VS; (c) Base station JRSP Kantor Pertanahan Kabupaten Sleman; (d) Pita ukur; (e) Total Station Leica TC 407; (f) Autocad Map 2004; (g) Program Topcon Link v.8.2; (h) Program PCCDU versi 2.1.14p Lite; (i) Program Topcon Tools v. 7.2; (j) Program Microsoft Excel versi 2007; (k) Program SPSS (Statistical Package for the Social Sciences) Statistics16.o; (l) Program Microsoft Office versi 2007; (m) Laptop Acer 293oZ; SIMCARD Simpati (Telkomsel); (n) Aplikasi Spiderweb BPN RI; (o) Aplikasi Arc Gis 9.3; (p) Aplikasi Google Earth.

\section{Populasi dan Sampel}

Dalam penelitian ini populasi adalah seluruh titik batas bidang tanah. Sedangkan sampel yang digunakan adalah 24 batas bidang tanah ( 15 bidang tanah). Pengambilan sampel dilakukan secara acak sederhana (simple random sampling) dimana setiap populasi memiliki kesempatan yang sama untuk diambil sebagai sampel penelitian.
5. Tahapan Pelaksanaan Penelitian

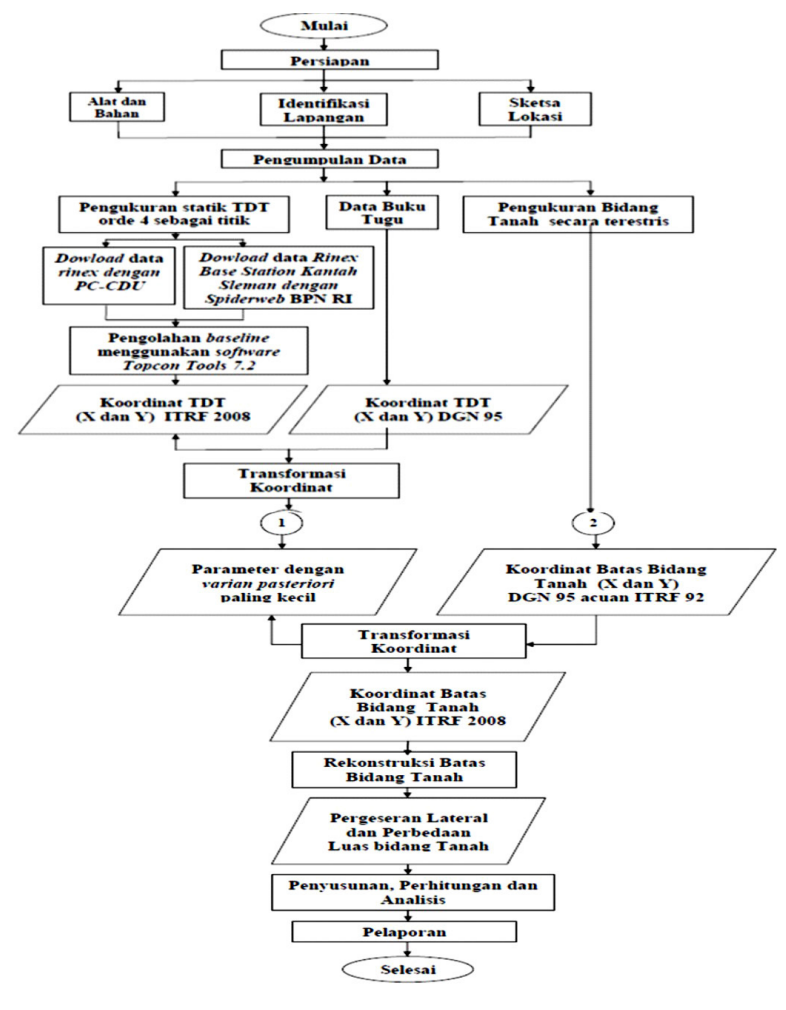

Gambar 4. Diagram Alir Penelitian

\section{Teknik Analisis Data}

Melaksanakan transformasi koordinat dengan metode Helmert, Affine dan Lauf. Mencari masingmasing varian pasteriorinya dengan rumus sebagai berikut:

$$
\sigma 2=\frac{\mathrm{v}^{\mathrm{T}} \mathrm{v}}{\mathrm{r}} .
$$

Keterangan

$\sigma 2=$ varianposteriori; $\mathrm{V}=$ Matrik residu dan

$\mathrm{r}=$ degree offreedom

Melaksanakan analisis data berdasarkan Juknis PMNA/K.BPN No 3 Tahun 1997 dan uji t.

a. Pergeseran Lateral

Berdasarkan Juknis PMNA/K.BPN No 3 tahun 1997 pergeseran lateral ini dengan nilai toleransi 10 cm daerah pemukiman dan $25 \mathrm{~cm}$ untuk daerah pertanian

Rumus pergeseran lateral;

$\mathrm{dLi}=\sqrt{(\mathrm{Xi}-\mathrm{xi})^{2}+(\mathrm{Yi}-\mathrm{yi})^{2}}$

Keterangan

$\mathrm{dLi}=$ Pergeseran Lateral titik I; Xi,Yi =Koordinat 
titik batas bidang tanah dalam Gambar Ukur; xi,yi =Koordinat titik batas bidang tanahhasil rekonstruksi JRSP.

Uji t (taraf á $=5 \%$ )

$$
\mathrm{t}=\frac{\mathrm{dL}}{\mathrm{s} / \sqrt{\mathrm{n}}}
$$

Keterangan : $\mathrm{dL}=$ Rata-rata penyimpangan lateral posisi; $\mathrm{S}$ = Simpangan Baku penyimpangan lateral; $\mathrm{n}=$ Jumlah sampel.

Untuk dapat menguji apakah harga $t_{\text {hitung }}$ perhitungan dengan rumus di atas sama dengan nol atau tidak berbeda secara signifikan, maka perlu dikonsultasikan dengan $t_{\text {tabel}}$, dengan memakai tingkat kepercayaan $95 \%$ dan besar derajat kebebasan untuk uji tadalah dengan n-1 (Sugiyono 2002, 93). Jika $t_{\text {tabel }} \leq t_{\text {hitung }} \leq+t_{\text {tabel, }}$ maka tidak terdapat perbedaan yang signifikan terhadap pergeseran lateral batas bidang tanah hasil rekonstruksi menggunakan JRSP.

b. Perbedaan Luas

Berdasarkan Juknis PMNA/K.BPN No 3 tahun 1997 toleransi perbedaan luasnya adalah sebagai berikut:

\section{$\mathrm{T}=1 / 2 \sqrt{\mathrm{L}}$}

Keterangan: $\mathrm{T}=$ Toleransi selisish/perbedaan

luas; $\mathrm{L}=$ Rata-rata luas

Uji t (taraf $\alpha=5 \%$ )

Keterangan $: \mathrm{e}=$ Nilai rata-rata perbedaan luas.;

$\mathrm{Se}=$ Simpangan baku perbedaan luas;

$\mathrm{n}$ = Jumlah sampel

Untuk dapat menguji apakah harga $t_{\text {hitung }}$ perhitungan dengan rumus di atas sama dengan nol atau tidak berbeda secara signifikan, maka perlu dikonsultasikan dengan $t_{\text {tabel }}$, dengan memakai tingkat kepercayaan $95 \%$ dan besar derajat kebebasan untuk uji tadalah dengan n-1(Sugiyono 2002, 93). Jika $t_{\text {tabel }} \leq t_{\text {hitung }} d^{\prime \prime}+t_{\text {tabell }}$ maka tidak terdapat perbedaan yang signifikan terhadap perbedaan luas bidang tanah hasil rekonstruksi menggunakan JRSP.

\section{Hasil dan Pembahasan}

\section{Transformasi Koordinat Datum Geodesi Nasional 1995 (DGN 95) dengan Acuan ITRF 92 ke ITRF 2008}

\section{a. Titik Sekutu Transformasi Koordinat}

Titik sekutu pada sistem koordinat lama adalah TDT yang dilaksanakan pengukuran tahun 1996 berdasarkan DGN 95 (ITRF 92 pada epoch 1993). Titik sekutu berdasarkan sistem koordinat baru yaitu ITRF 2008 diukur secara statikpengolahan data post processing yang diikatkan menggunakan titik tetap dari base station JRSP Kantor Pertanahan Kabupaten Sleman. Pengukuran statiknya menggunakan alat Topcon Hyper Ga. Data rinexbase station JRSP Kantor Pertanahan Kabupaten Sleman diperoleh dengan melakukan pengunduhan melaui spiderweb BPN RI yang dapat diakses pada $\underline{h t t p: / / ~}$ www.bpnri-cors.net/spiderweb. Pengolahan data post processing menggunakan software komersial Topcon Tools 7.2demo mode tanpa menggunakan dongle di karenakan titik yang akan diolah hanya 5(lima) buah titik.

Pada hasil pengolahan data diketahui bahwa dengan jarak baseline sekitar $8 \mathrm{~km}$ didapat horizontal precision 0,003 $\mathrm{m}$ (pada baseline SLM1-TDT 002), o,003 m (pada baseline SLM1-TDT103P), 0,004 (pada baseline TDT B1"TDT TB2), o,ooım (pada baseline TDTTB1"TDT oo2), o,oo1m (pada baseline TDT TB2"TDT 002), o,oo1m (pada baseline TDT TB2"TDT ${ }_{103} \mathrm{P}$ ) dan o,oo1m (pada baseline TDT 002"TDT 103P).Dikarenakan perbedaan pengikatan tersebut maka koordinat yang dihasilkan pun berbeda. Besar dan arah pergeseran lateral akibat perbedaan pengikatan antara DGN 95 dengan acuan ITRF 92 dan ITRF 2008 dapat di lihat pada tabel 2 berikut ini : 
Tabel 2. Titik Sekutu Transformasi Koordinat

\begin{tabular}{|c|c|c|c|c|c|c|c|c|c|c|}
\hline \multirow[t]{2}{*}{ Titik } & \multicolumn{2}{|c|}{$\begin{array}{c}\text { Koordinat lama ( DGN } 95 \\
\text { acuan ITRF 92) }\end{array}$} & \multicolumn{2}{|c|}{$\begin{array}{c}\text { Koordinat Baru ( ITRF } \\
\text { 2008) }\end{array}$} & \multirow[t]{2}{*}{$\Delta \mathrm{X}(\mathbf{m})$} & \multirow[t]{2}{*}{$\Delta \mathrm{Y}(\mathbf{m})$} & \multirow[t]{2}{*}{$\Delta \mathbf{L}(\mathbf{m})$} & \multicolumn{3}{|c|}{ Azimuth } \\
\hline & $\mathrm{X}(\mathrm{m})$ & $\mathbf{Y}(\mathbf{m})$ & $\mathbf{X}(\mathbf{m})$ & $\mathbf{Y}(\mathbf{m})$ & & & & $\mathbf{0}$ & 1 & $"$ \\
\hline TDT oo2 & 292929.439 & 639386.131 & 292930.044 & 639386.890 & 0.605 & 0.759 & 0.971 & 38 & 33 & 30.24 \\
\hline TDT ${ }_{103} \mathrm{P}$ & 293088.510 & 639325.651 & 293089.115 & 639326.409 & 0.605 & $0.75^{8}$ & 0.970 & 38 & 35 & 32.41 \\
\hline TDT TB 2 & 293066.491 & 639220.045 & 293067.096 & 639220.804 & 0.605 & 0.759 & 0.971 & 38 & 33 & 30.24 \\
\hline TDT TB 1 & 292902.266 & 639261.475 & 292902.871 & 639262.234 & 0.605 & 0.759 & 0.971 & 38 & 33 & 30.24 \\
\hline
\end{tabular}

Sumber: Hasil Pengolahan Data Primer Tahun 2014.

Berdasarkan tabel 2 tersebut dapat diketahui bahwa besarnya pergeseran lateral pengukuran terhadap DGN 95 dengan acuan ITRF 92 dan ITRF 2008 adalah 0,971 meter, sedangkan arah pergeseranya adalah $38^{\circ} 33^{\prime} 30,24^{\prime \prime}$ dari titik utara.

Menurut Subarya $(2013,15)$ perihal DGN 95 dengan laju kecepatan (velocity rate) permukaan pulau jawa rata-rata $27 \mathrm{~mm} /$ tahun. Dengan melihat hal tersebut bahwa pada tahun 2014 ini waktu telah berlalu \pm 18 tahun sejak 12 februari 1996. Sehingga posisi awal telah berubah sebesar $18 \times 27 \mathrm{~mm}=$ $486 \mathrm{~mm}=0,486$ meter. Namun dalam hal ini hasil perhitungan terdapat $\pm 0,971$ meter perbedaan mengikat antara ITRF 2008 dan DGN 95 acuan ITRF 92. Perbedaan yang cukup signifikan antara ITRF 2008 dengan DGN 95 dengan acuan ITRF 92 disebabkan oleh karena dokumentasi pendefinisian mengenai DGN 95 yang masih kurang jelas (Mustaqim 2013, 52).

Selain itu Mausaura $(2012,49)$ pergeseran TDT yang ada di wilayah Kabupaten Bantul terdapat pada kuadran yang sama yaitu kuadran I atau ke arah utara timur. Arah pergeseran utara timur ini sama dengan hasil penelitian penulis di Desa Banyuraden, Kecamatan Gamping, Kabupaten Sleman. Arah pergeseran ini kemungkinan terjadi kesalahan sistematik yang dipengaruhi oleh beberapa faktor. Salah satu faktor adalah gempa bumi Yogyakarta pada tahun 2006yang mengguncang kawasan Bantul, Yogyakarta, Sleman, dan Klaten. Merujuk pada penelitian yang dilakukan oleh Abidin, dkk (2009, 10), nampak bahwa deformasi koseismikgempa Yogyakarta pada tahun 2006 sebesar 10 sampai dengan $15 \mathrm{~cm}$ dan deformasi pascaseismik hingga tahun 2008 sebesar o,3 sampai dengan 9,1 cm. Jadi, masih besar kemungkinan pergerakan pascaseismik terus berlanjut hingga diadakan penelitian ini.

Faktor lain menurut Andreas dkk (2011, 9) permasalahan status geometrik dari titik-titik kerangka dasar pemetaan nasional akibat konsekuensi dari dinamika bumi, dan akibat ketidakcermatan dalam pengolahan data. Permasalahan ini baik kita sadari atau tidak akan mempengaruhi pekerjaan survei dan pemetan.Faktor lainnyaadalah karena cara pengukuran yang berbeda.Oleh karena itu, perlu dilakukan pengkajian lanjut sebab perbedaanya yang bersifat sistematis ini.

\section{b. Parameter dan Varian Posteriori}

\section{Transformasi Koordinat}

Terdapat beberapa model dalam transformasi koordinat yang digunakan di lingkungan BPN RI diantaranya metode Helmert, metode Affine dan metode Lauf. Parameter masing-masing metode dapat dilihat pada tabel 3, 4 dan 5 berikut:

Tabel 3. Parameter Transformasi Metode Helmert

\begin{tabular}{cc}
\hline Parameter & Nilai \\
\hline P & 0.999999367 \\
\hline$Q$ & $-2.15322 \mathrm{E}-06$ \\
\hline A & -0.5859375 \\
\hline B & 1.796875 \\
\hline
\end{tabular}

Sumber: Hasil Pengolahan Data Primer Tahun 2014. 
Tabel 4. Parameter Transformasi Metode Affine

\begin{tabular}{cc}
\hline Parameter & Nilai \\
\hline A & 1.000000011 \\
\hline B & $7.45058 \mathrm{E}-09$ \\
\hline C & $-4.03076 \mathrm{E}-06$ \\
\hline D & 0.99999693 \\
\hline C1 & 0.59375 \\
\hline C2 & 3.90625 \\
\hline
\end{tabular}

Sumber: Hasil Pengolahan Data Primer Tahun 2014.

Tabel 5. Parameter Transformasi Metode Lauf

\begin{tabular}{cc}
\hline Parameter & Nilai \\
\hline a1 & $9.53674 \mathrm{E}-07$ \\
\hline a2 & $-5.72205 \mathrm{E}-06$ \\
\hline b1 & 0.25 \\
\hline b2 & 2 \\
\hline C1 & 524288 \\
\hline C2 & 0 \\
\hline
\end{tabular}

Sumber: Hasil Pengolahan Data Primer Tahun 2014.

Hitungan transformasi koordinat metode Helmert, metode Affine dan metode Lauf tersebut menghasilkan varian posteriorisebagaimana di tunjukkan pada tabel 6 sebagai berikut:

Tabel 6. Varian Posteriori Transformasi Koordinat

\begin{tabular}{cccc}
\hline No & Metode & Data Lebih & Varian Posteriori \\
\hline & Transformasi & $<\mathrm{r}>$ & $<\boldsymbol{\sigma 2}>$ \\
\hline 1 & Helmert & 4 & 1.143020313 \\
\hline 2 & Affine & 2 & 8.805661004 \\
\hline 3 & Lauf & 2 & $1.37439 \mathrm{E}+11$ \\
\hline
\end{tabular}

Sumber: Hasil Pengolahan Data Primer Tahun 2014.

Berdasarkan tabel 6 tersebut dapat di ketahui bahwa varian posteriori transformasi koordinat metode Helmert lebih kecil dibandingkan transformasi koordinat metode Affine dan metode Lauf sehingga metode transformasi koordinat yang paling teliti adalah metode Helmert.

\section{c. Transformasi Koordinat Batas Bidang Tanah}

Sebelum di lakukan rekonstruksi batas bidang tanahmenggunakan JRSP, koordinat batas bidang tanah hasil pengukuran secara terestris pengikatan ke DGN 95 dengan acuan ITRF 92 ditransformasikan ke ITRF 2008 menggunakan transformasi koordinat metode Helmert dengan parameter sesuai dengan tabel 3.

Secara visual hasil dari transformasi koordinat batas bidang tanah menggunakan metode Helmert menghasilkan bentuk konform (sama bentuk/sama sudut), hal inidapat di lihat pada gambar 5 berikut:

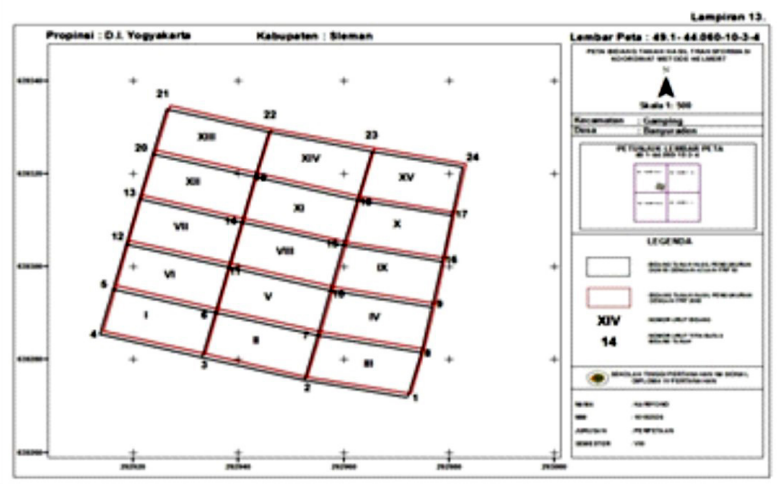

Gambar. 5. Peta Hasil Transformasi Koordinat Batas Bidang Tanah Menggunakan Metode Helmert. (Sumber : Pengolahan Data Primer Tahun 2014)

2. Pergeseran Lateral dan Perbedaan Luas Bidang TanahHasil Rekonstruksi

BatasBidang Tanah Menggunakan Jaringan Referensi Satelit Pertanahan

\section{a. Pergeseran Lateral Hasil Rekonstruksi}

Batas Bidang Tanah Menggunakan JRSP

Sebelum dilaksanakan pengukuran rekonstruksi batas bidang tanah menggunakan JRSP terlebih dahulu data koordinat batas bidang tanah hasil pengukuran terestris yang sudah ditransformasi koordinat ke ITRF 2008 dimasukkan ke dalam rover Javad Triumph -VS dan dilakukan setting alat sesuai buku panduan.

Sebelum pelaksanaan rekonstruksi batas bidang tanah menggunakan JRSP dengan alat rover Javad Triumph-VS di pastikan pada alat solusi RTK fixed baru selanjutnya di lakukan pencarian titik batas yang akan di rekonstruksikan di lapangan. Dalam penelitian ini data yang akan direkonstruksikan menggunakan proyeksi TM $3^{\circ}$. Hasil rekonstruksi 
batas bidang tanah tersebut dapat di lihat pada tabel 7 berikut:

Tabel 7.Pergeseran Lateral Hasil Rekonstruksi Menggunakan JRSP

\begin{tabular}{|c|c|c|}
\hline \multirow{2}{*}{ Titik } & \multicolumn{2}{|c|}{ Pergeseran Lateral Hasil Rekonstruksi } \\
\cline { 2 - 3 } & Jarak $(\mathbf{m})$ & Arah \\
\hline 1 & 0.070 & Utara- Timur \\
\hline 2 & 0.052 & Utara- Timur \\
\hline 3 & 0.048 & Utara- Timur \\
\hline 4 & 0.050 & Utara- Timur \\
\hline 5 & 0.042 & Utara- Timur \\
\hline 6 & 0.045 & Utara- Timur \\
\hline 7 & 0.044 & Utara- Timur \\
\hline 8 & 0.070 & Utara- Timur \\
\hline 9 & 0.060 & Utara- Timur \\
\hline 10 & 0.052 & Utara- Timur \\
\hline 11 & 0.050 & Utara- Timur \\
\hline 12 & 0.050 & Utara- Timur \\
\hline 13 & 0.047 & Utara- Timur \\
\hline 14 & 0.050 & Utara- Timur \\
\hline 15 & 0.040 & Utara- Timur \\
\hline 16 & 0.066 & Utara- Timur \\
\hline 17 & 0.060 & Utara- Timur \\
\hline 18 & 0.042 & Utara- Timur \\
\hline 19 & 0.050 & Utara- Timur \\
\hline 20 & 0.050 & Utara- Timur \\
\hline 21 & 0.048 & Utara- Timur \\
\hline 22 & 0.048 & Utara- Timur \\
\hline 23 & 0.050 & Utara- Timur \\
\hline 24 & 0.078 & Utara- Timur \\
\hline
\end{tabular}

Sumber: Hasil Pengolahan Data Primer Tahun 2014.

Secara visul pergeseran lateral tersebut dapat dilihat pada gambar 6 berikut ini:

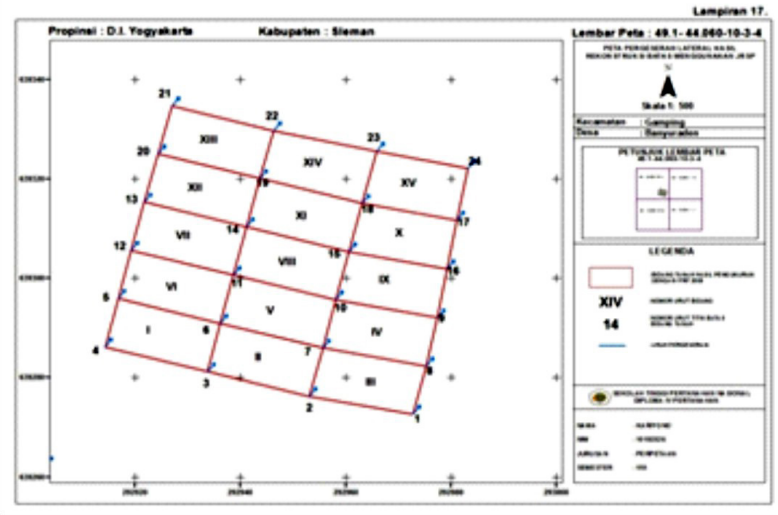

Gambar 6. Peta Pergeseran Lateral Hasil Rekonstruksi Batas Bidang Tanah Menggunakan JRSP. (Sumber : Pengolahan Data Primer Tahun 2014)
Teknik analisis data terhadap pergeseran lateral batas bidang tanah menggunakan dua cara yaitu sebagai berikut:

1) Juknis PMNA/K.BPN No 3 Tahun 1997

Sesuai dengan tabel 7 tersebut terlihat bahwa pergeseran lateral hasil rekontruksi batas bidang tanah menggunakan JRSP terendah sebesar $4 \mathrm{~cm}$ meter s/d 7,8 meter. Toleransi pergeseran lateral yang ditetapkan berdasarkan Juknis PMNA/KBPN No 3 Tahun 1997 adalah $10 \mathrm{~cm}$ untuk daerah pemukiman dan $25 \mathrm{~cm}$ untuk daerah pertanian. Dengan demikian, pergeseran hasil rekonstruksi batas bidang tanah menggunakan JRSP memenuhi syarat toleransi yang telah disyaratkan.

2) Ujit

Uji t (two tail test)pergeseran lateral pada taraf signifikansi $(\alpha)$ 5\% menggunakan SPSS 16.0 dan hasilnya dapat dilihat pada tabel 8 berikut:

Tabel 8. Hasil uji t Pergeseran Lateral $\alpha=0,05$ dengan SPSS 16.0 One-Sample Test

\begin{tabular}{|c|c|c|c|c|}
\hline & $\mathrm{N}$ & Mean & Std. Deviation & Std. Error Mean \\
\hline Pergeseran & 24 & .0526 & .00978 & .00200 \\
\hline
\end{tabular}

Sumber: Pengolahan data primer dengan SPSS I6.o, Tahun 2014

One-Sample Test

\begin{tabular}{|c|c|c|c|c|c|c|}
\hline & \multirow[t]{2}{*}{$\mathrm{t}$} & \multirow[t]{2}{*}{ Df } & \multirow[t]{2}{*}{$\begin{array}{l}\text { Sig. (2- } \\
\text { tailed) }\end{array}$} & \multirow[t]{2}{*}{$\begin{array}{c}\text { Mean } \\
\text { Difference }\end{array}$} & \multicolumn{2}{|c|}{$\begin{array}{l}95 \% \text { Confidence } \\
\text { Interval of the } \\
\text { Difference }\end{array}$} \\
\hline & & & & & Lower & Upper \\
\hline Pergeseran & 1.295 & 23 & .208 & .00258 & -.0015 & .0067 \\
\hline
\end{tabular}

Berdasarkan tabel 8 diatas maka dapat dilihat bahwa $t_{\text {hitung }}=1.295$ sedangkan $t_{\text {tabel }} \pm 2.069$ dalam

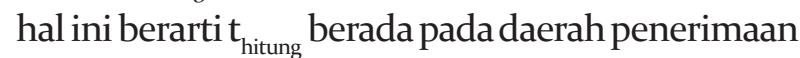
yang dapat di lihat pada kurva berikut:

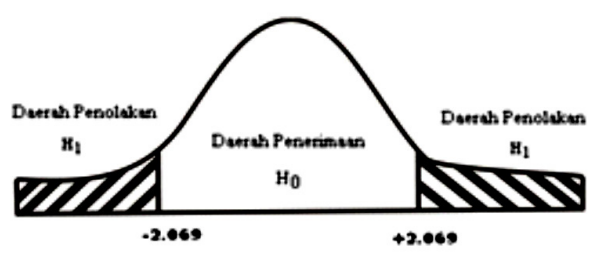

Gambar 7. Nilai Kritis Pengujian Two Tail untuk $\alpha=5 \% \mathrm{df}=23$. 
Selain itu $p$-value $(2$ tailed $)=0,208$ lebih besar dari $\alpha=0,05$, maka dapat disimpulkan bahwa tidak terdapat perbedaan signifikan terhadap pergeseran lateral batas bidang tanah hasil rekonstruksi batas bidang tanah menggunakan JRSP.

\section{b. Perbedaan Luas bidang Tanah Hasil \\ Rekonstruksi Batas Bidang Tanah Menggunakan JRSP}

Teknik analisis data terhadap perbedaan luas bidang tanah menggunakan dua cara yaitu sebagai berikut:

1) Juknis PMNA/K.BPN No 3 Tahun 1997

Tabel 9.Perbedaan Luas bidang Tanah Hasil Rekonstruksi Menggunakan JRS

\begin{tabular}{crccc}
\hline $\begin{array}{c}\text { No } \\
\text { Bidang }\end{array}$ & $\mathrm{L}$ & $? \mathrm{~L}\left(\mathrm{~m}^{2}\right)$ & $\begin{array}{c}\mathrm{T}( \pm 1 / 2 ? \mathrm{~L}) \\
(\mathrm{m} 2)\end{array}$ & $\begin{array}{c}\text { Penerimaan } \\
(\text { Ya/Tidak })\end{array}$ \\
\hline I & 199.47 & 0.000253 & 7.062 & Ya \\
\hline II & 200.6705 & 0.000254 & 7.083 & Ya \\
\hline III & 201.9094 & 0.000256 & 7.105 & Ya \\
\hline IV & 200.3025 & 0.000254 & 7.076 & Ya \\
\hline V & 200.7774 & 0.000254 & 7.085 & Ya \\
VI & 197.7156 & 0.00025 & 7.031 & Ya \\
VII & 193.2498 & 0.000245 & 6.951 & Ya \\
\hline VIII & 201.0995 & 0.000255 & 7.090 & Ya \\
IX & 201.4282 & 0.000255 & 7.096 & Ya \\
X & 201.0632 & 0.000255 & 7.090 & Ya \\
XI & 200.5864 & 0.000254 & 7.081 & Ya \\
\hline XII & 186.5067 & 0.000236 & 6.828 & Ya \\
\hline XIII & 193.2802 & 0.000245 & 6.951 & Ya \\
\hline XIV & 208.6093 & 0.000264 & 7.222 & Ya \\
XV & 199.9229 & 0.000253 & 7.070 & Ya \\
\hline
\end{tabular}

Sumber: Hasil Pengolahan Data Primer Tahun 2014.

Berdasarkan Petunjuk Teknis PMNA/KBPN No 3 Tahun 1997 bahwa syarat dari perbedaan luas adalah T $=1 / 2$ "L. Dalam tabel 9 tersebut dapat dilihat bahwa untuk bidang tanah I s/d XV diterima atau memenuhi toleransi yang dipersyaratkan.

\section{2) Ujit}

Uji t (two tail test)perbedaan luas pada taraf signifikansi $(\alpha)$ 5\% menggunakan SPSS 16.o dan hasilnya dapat dilihat pada tabel o berikut:
Tabel 10. Hasil uji tPerbedaan Luasá = 0,05 dengan SPSS 16.0

One-Sample Test

\begin{tabular}{|c|c|c|c|c|}
\hline & $\mathrm{N}$ & Mean & Std. Deviation & $\begin{array}{c}\text { Std. Error } \\
\text { Mean }\end{array}$ \\
\hline Perbedaan_Luas & 15 & .000252187 & .0000063325 & .0000016351 \\
\hline
\end{tabular}

One-Sample Test

\begin{tabular}{|c|c|c|c|c|c|c|}
\hline & \multirow[b]{2}{*}{$\mathrm{T}$} & \multirow[b]{2}{*}{$\mathrm{df}$} & \multirow{2}{*}{$\begin{array}{l}\text { Sig. (2- } \\
\text { tailed) }\end{array}$} & \multirow{2}{*}{$\begin{array}{c}\text { Mean } \\
\text { Difference }\end{array}$} & \multicolumn{2}{|c|}{$\begin{array}{c}95 \% \text { Confidence Interval } \\
\text { of the Difference }\end{array}$} \\
\hline & & & & & Lower & Upper \\
\hline $\begin{array}{l}\text { Perbedaan } \\
\text { Luas }\end{array}$ & 1.337 & 14 & .202 & .0000021869 & -.000001320 & .000005694 \\
\hline
\end{tabular}

Sumber: Pengolahan Data Primer dengan SPSS I6.0, Tahun 2014

Berdasarkan tabel 10 diatas maka dapat dilihat bahwa $t_{\text {hitung }}=1.337$ sedangkan $\mathrm{t}_{\text {tabel }} \pm 2.145$ dalam hal ini berarti $t_{\text {hitung }}$ berada pada daerah penerimaan yang dapat di lihat pada kurva berikut:

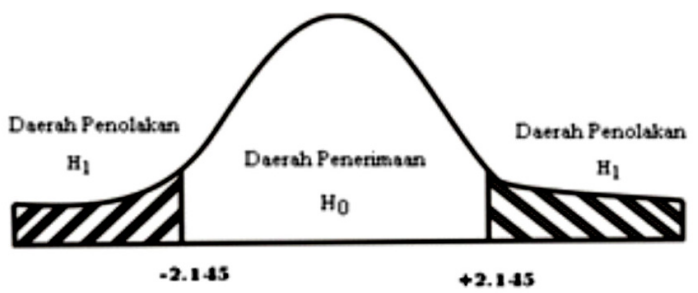

Gambar 8. Nilai Kritis Pengujian Two Tail untuk $\alpha=5 \% \mathrm{df}=\mathrm{I} 4$.

Selain itu $p$-value $(2$ tailed $)=0,202$ lebih besar dari $\alpha=0,05$, makadapat disimpulkan bahwa tidak terdapat perbedaan signifikan terhadap perbedaan luas bidang tanah hasil rekonstruksi batas bidang tanah menggunakan JRSP.

\section{E. Kesimpulan dan Saran}

Berdasarkan hasil dan pembahasan maka dapat ditarik kesimpulan yaitu :

1) Rekonstruksi batas bidang tanah tanah menggunakan JRSP dapat dilaksanakan dengan terlebih dahulu melaksanakan transformasi koordinat dan metode Helmert merupakan metode paling teliti dengan varian posteriori () 
$=1.143020313$.

2) Pergeseran lateral hasil rekonstruksi batas bidang tanah dengan rata-rata 0.053 meter memenuhi syarat toleransi yang disyaratkan Juknis PMNA/KBPN No 3 Tahun 1997 yaitu 10 $\mathrm{cm}$ untuk daerah pemukiman, $25 \mathrm{~cm}$ untuk daerah pertanian dan dari uji t pergeseran lateral $\left(\alpha=5 \%, \mathrm{df}=23, \mathrm{t}_{\text {hitung }}=1.295\right.$, dan $p$-value $=$ o,208) tidak terdapat perbedaan yang signifikan terhadap pergeseran lateral hasil rekonstruksi batas bidang tanah menggunakan JRSP. Untuk perbedaan luas hasil rekonstruksi batas bidang tanah dengan rata-rata $0.000252 \mathrm{~m}^{2}$, memenuhi syarat toleransi sesuai Juknis PMNA/KBPN No 3 Tahun 1997 yaitu $\mathrm{T}=1 / 2 \sqrt{ } \mathrm{L}$ dan dari uji t perbedaan luas $\left(\alpha=5 \%, \mathrm{df}=14, \mathrm{t}_{\text {hitung }}=1.337\right.$ dan $p$-value $=0,202)$ tidakterdapat perbedaan signifikan terhadapperbedaan luas bidang tanah hasil rekonstruksi batas bidang tanah menggunakan JRSP.

Dari penelitian ini, terdapat beberapa saran yang dapat diberikan untuk kemajuan penelitian selanjutnya, yaitu :

1) Perlunya pembenahan sistem pengelolaan stasiun JRSP BPN RI karena sistem yang selama ini terpusat dan terkadang sedang dalam keadaan maintenance menyebabkan download data RINEX stasiun JRSP Kantor Pertanahan KabupatenSleman cukup lama;

2) BPN RI di harapkan mampu mengoptimalkan pemanfaatan JRSP salah satunya untuk pelaksanaan rekonstruksi batas bidang tanah;

3) Perlu dilakukan pendefinisian ulangkoordinat tetap (fixed point) basestation JRSP Kantor Pertanahan Kabupaten Sleman secara berkala oleh BPN RI. Hal ini untuk mengetahui tingkat perubahan posisi base station dan terkait konsep penerapan JRSP untuk dynamic cadastre.

\section{Daftar Pustaka}

Abidin,H.Z 2001,Geodesi satelit, Jakarta: Pradnya Paramita.

, 2005, 'Rekonstruksi batas persil tanah di Aceh pasca tsunami: beberapa aspek dan permasalahannya', Jurnal Infrastruktur dan Lingkungan Binaan, Vol. I No. 2 h. 1-10. , 2006, Penentuan posisi dengan gps dan aplikasinya, Jakarta: P.T. Pradnya Paramita.

Andreas, Heri 2011, Epoch Refrence 2012, FIT ISI dan seminar nasional 2011, Semarang, 24 November 2011.

Badan Pertanahan Nasional 1998, Petunjuk teknis PMNA/K.BPNNo. 3 tahun 1997: materipengukuran dan pendaftaran tanah,Badan Pertanahan Nasional, Jakarta.

Badan Pertanahan Nasional 2001, Pegangan petugas ukur: materi pengukuran dan pemetaan kadastral, Deputi Bidang Informasi Pertanahan, Badan Pertanahan Nasional, Jakarta.

Badan Pertanahan Nasional RI 2009, Pelaksanaan pengukuran dan pemetaan bidang tanah dengan CORS/JRSP, Deputi Survei Pengukuran dan Pemetaan BPN Republik Indonesia, Jakarta.

Badan Pertanahan Nasional RI 2009, Pedoman dan petunjuk teknis jaringan referensi satelit pertanahan, Deputi Survei Pengukuran dan Pemetaan Badan Pertanahan Nasional Republik Indonesia, Jakarta.

Badan Standarisasi Nasional 2002, Standart Nasional Indonesia jaring kontrol horisontal SNI 196724-2002, Jakarta.

Jurusan Teknik Geodesi FTSP ITB 1997, Petunjuk penggunaan proyeksi TM 30 dalam pengukuran dan pemetaan kadastral, kbk pemetaan sistematik dan rekayasa. Bandung.

Kurniawan, Buyung dkk 2004, 'Uji perbandingan metode lauf dan affine dalam transformasi koordinat sistem lokal ke sistem nasional, Jurnal Widya Bhumi STPN, Yogyakarta No 15 Tahun 6 November 2006, h.1-13.

Mardiyono, Yuli dan Arief Syaifullah 2009, Materi pokok pengukuran dan pemetaan kadastral II, Cetakan Pertama, Sekolah Tinggi Pertanahan Nasional, Yogyakarta.

Meilano, Irwan dkk 2012, 'Analisis deformasi gempa 
mentawai tahun 2010 berdasarkan data pengamatan GPS kontinu tahun 2010-2011'. Jurnal Geofisika Vol. 13 No. 2 h. 42-51.

Musaura, Amon Yoga2012, Pemanfaatan GNSS CORS untuk penentuan titik dasar teknik orde 3 menggunakan metode rapid static dengan moda radial, Skripsi, Yogyakarta: Jurusan Teknik Geodesi , Fakultas Teknik UGM.

Mustaqim, Miftah 2013, Perbandingan antara hasil pengamatan GPS JRSP metode single base dan multi base, Skripsi, Program DIV STPN Yogyakarta.

Nugroho, Tanjung 2004, 'Bagaimanakah gambar ukur yang standart? 'Jurnal Widya Bhumi STPN, Yogyakarta No. 14 Tahun 5 h.8-14.

Nugroho, Tanjung 2005,'Distorsi bentuk dalam transformasi dari UTM keTM $3^{\circ}$, Jurnal Widya Bhumi STPN, Yogyakarta No. 13 Tahun 5 Desember 2005 h. 26-33.

Nugroho, Tanjung 2013, 'Kadaster 4D: sebuah keniscayaan menurut kondisi geologis Indonesia', Jurnal Ilmiah Pertanahan Bhumi, No. 38 Tahun 12, Oktober 2013, hal 253-262.
Subarya, Cecep 2004, Jaring kontrol geodesi nasional dengan pengukuran global positioning system dalam itrf 2000 epoch 1998, Bogor: Bakosurtanal Pusat Geodesi dan Geodinamika. Sugiyono 2002,Statistika untuk penelitian. Bandung: CV Alfabeta.

Sunantyo, T.A 2009, GNSS CORS infrastructure and standard in Indonesia, 7th FIG Regional Conference, 19-22 October 2009, Hanoi, Vietnam.

Sunantyo, T.A 2010, 'Tinjauan status titik dasar teknik dan prospeknya di masa mendatang bagi BPN-RI', Makalah Seminar Nasional GNSS-CORS, Jurusan Teknik Geodesi FT, Universitas Gadjah Mada, Yogyakarta.

Sunantyo, T.A dan Jawahir F 2011, 'Jaring kontrol geodetik dinamik di wilayah tektonik Indonesia', FIT ISI dan Seminar Nasional 2011, Semarang, 24 November 2011. 